\title{
THE RELATION BETWEEN ONLINE PROTECTION REGULATIONS AND THE INTENTION TO USE E-SERVICES/AGE PERSPECTIVE: A CASE STUDY FROM HUNGARY
}

\author{
Author(s): \\ Pierre Alassaf ${ }^{1}$, Miriam Bahna ${ }^{2}$, Basem Munir El-assaf ${ }^{3}$ \\ Affiliation: \\ 1,2 Szent István University, Doctoral School of Management and Business Administration, 2100 Gödöllö, Páter K. u. 1 \\ ${ }^{3}$ Budapest Business School, Faculty of Finance and Accountancy, Buzogány u. 10-12, 1149, Budapest. \\ Email address: \\ pierrealassaf@hotmail.com; miriam.bahna@phd.uni-szie.hu; basem_assaf2000@yahoo.com
}

\begin{abstract}
As more regulations to protect privacy and security for online interactions is carrying out, as more complications to perform these transactions is coming forward, affecting the intention to execute these interactions online especially for old people. This study aims to reveal the relation between intention to use high secured e-services with the age of user. This study finds that there is a positive relation between the over-40 years online users' ages and their retreating from completing online transactions due the complications of security and privacy procedures. Also, the study finds that $85 \%$ of people feel more comfortable to execute their transactions online with the high secure regulation, but from another perspective, $60 \%$ of persons between 40-55 years old don't prefer doing their transactions online due to the complication of transaction security procedures, where $92 \%$ of people over 65 are avoiding to do financial transaction online and they need another person help to perform it more than $82 \%$ of times.
\end{abstract}

Keywords: E- services, online security, digital gap, 40 plus people, intention

\section{Introduction}

New technology applications are extremely introducing into our daily life in an increasing basis, this highspeed change make it harder for old people to adapt at the same speed of the new generation, and that causes a digital divide between generations (Millward, 2003), for instance, in 2019, 23\% European people aged between 55 and 74 are not using internet at all, where all new generation (digital-native) are using it (European Commission, 2020). This digital gap between generation deserves to be studied thoughtfully, but on the other hand, the information communication technologies offer a great opportunity to the older generation to stay connected socially with their far-distance families and friends, also it enables them to execute their activities remotely, besides to the online health care, learning and entertainment platforms, in general ICTs enhance the life quality of old generation (Schreurs et al., 2017; Bercovitz and Pagnini, 2016).

From another perspective there are people don't use ICTs, Van Dijk (1999) noticed this phenomenon and described four possible groups of factors that impede using ICTs, first one related to lack of motivation to use computers and internet, second group related to personal skills or computer literacy, third related to accessibility to internet in region the user exists, and the last groups comes from personal ability to afford costs of using technology, a little thinking about the lack of motivation to use ICTs drives the researchers to think about a group of factors such as attitude toward ICTs which in turn related to perceived security and privacy, in this context, security and privacy are considered vital barriers to use ICTs and e-services provided by e-government (Ahmad et al., 2013; Parent et al., 2005).These barriers of online security and privacy have pushed governments to develop policies and regulation to protect online interactions and encourage users to use virtual medium to execute their transaction and benefit from e-government services (Toots 2019; Osborne and Brown, 2011), but exerting online protection policies and regulation have brings a lot of complication and more steps that are not convenient to normal users especially when the age of user is bigger and drifting away of digital-natives ages (Sarah and Lock, 2016(. 


\section{Literature review}

In this section the study will brows literature and discuss the protection concept of online interactions from security, privacy and ease of use perspectives and their relations with the users' ages.

\section{Security of online interactions and users' age}

Al-Shboul et al (2014) and Alomari et al. (2009) have defined security of online medium as a key factor affecting successful implementation of e-governments and adopting its services, and Gilbert and Balestrini (2004) has considered that the security and trust in financial activities has a vital role in users' willing to use internet in executing their transactions, in this regards, privacy and security intersect in people minds to form a behavior that tends protect an anticipated risk (Belanger and Carter, 2008), here, Kowalewski et al. (2015) and Bergstrom (2015) saw that older users are more careful in using of their credit cards in secure online space than the younger users who concentrate their attention more on privacy disclosure on Social networking Sites, from another perspective, the perceived online security from older users point of view led to a wide diversity of and fined-spread privacy preferences (Hornung et al., 2017; Garg et al., 2012).

\section{Privacy of online interactions and users' age}

In spite of that the impact of online privacy on users' attitudes to use e-services has been confirmed (Waidner and Kasper, 2016; Angst and Agarwal, 2009; Parasuraman et al.,2005) there is no common consensus about the age impact on the uses' attention toward online privacy issues, as Miltgen \& Peyrat-Guillard (2014) and Van den Broeck et al. (2015) found that older online users are more sensitive to the privacy issues, whereas many other studies found no relation between age of the online user and his sensitivity to the privacy issues (Taddicken, 2014; Hoofnagle et al., 2010). In the same context, younger users use internet in more protective way for their privacy (Blank et al., 2014), while the older concern more about the privacy but when they act they show less protective behavior (Van den Broeck et al., 2015). This contradiction between higher privacy concerns and less protective behavior among older user of internet may come from their perceived practical complications of privacy and security measures applied on online interactions, and this reason is what this study is trying to prove.

\section{Perceived ease of use and age}

More and more of small smart devices are intervening widely in online interactions, and make it easier to interact and accomplish transactions anywhere with these smart portable devices (OECD, 2012), but these smart instruments have some limitation to be easy used such as smaller screens, many passwords to keep and relative complicated security procedures for online transactions which making it more uncomfortable for older users and more risky (Coventry and Briggs, 2016; Sarah and Lock, 2016) as they sometimes try to avoid the complication by putting more easier and predictable passwords or asking for assistance from others to read or overcome some protection measures which seem unfamiliar or complicated for them (West, 2015; Age UK , 2015; Karp and Wilson, 2011).

\section{Conceptual framework and hypothesis development}

As discussed in literature review paragraph about the contradiction between online older users' high concern in privacy and security issues and with their less careful protective behavior about them when they use internet and benefit from e-services (Blank et al., 2014; Van den Broeck et al., 2015) even when they accomplish their financial transactions and payment. The older users in general, due to Sarah and Lock (2016), need more support than younger in doing their banking transactions, as they are less flexible and have less ability to adapt quickly with continuous changing protecting requirements and procedures that may drive them to ask for personal help from others, which in turn make them more vulnerable to fraudulence and scam (Davidson, 2018). From this point, this study tries to observe the impact of complications come from protecting procedures of online transactions on the tendency to use online services from the users' ages perspective.

At the beginning, this research needs to test the relation between people' intentions to use online services on one side and privacy and security regulations and procedures on the other side, in the study environment. 
H1: There is a positive relation between online protecting procedures and people's intention to use online interactions.

To be more precise this study will focus on the effects of protecting procedures of online interactions on the tendency to use online services.

H2: Complications of protecting procedures of online interactions effects people's intention to complete online interactions.

To answer the question about the contradiction between online older users' high concern in privacy and security issues with their less careful protective behavior about these issues when they use internet, this research will measure the effect of complications come from protecting procedures of online interactions on people over-40 years old intention to complete online interactions.

H3: Complications of protecting procedures of online interactions effects over- 40 years people's intention to complete online interactions.

Testing these hypotheses would enhance the understanding the impacts of privacy and security online regulation and policies on users' intentions to perform their transactions and interacting online from age aspects.

\section{Importance of the study:}

Many researches have concerned in older age perceived privacy and security and their intention to use internet and online services, but this research provide a novelty in discussing the complications impact of online protecting procedures on online users' intentions to continue using e-services and online interactions in the light of the users' age.

\section{Methodology}

To test research hypotheses and answer the study questions this study will conduct a quantitative research based on distributing questionnaire in small cities in Hungary, not rural but not also in Budapest or large cities, to test hypotheses in moderate-developed regions in regards of ICTs advancement. The questionnaire collects demographic information about interrogators and their exact age due the importance of age for analyzing collected data for this study. Then questionnaire measures people intention to use e-government services and online application to accomplish their financial transactions.

Also, the questionnaire measures interrogated perceived privacy and security level of e-services in regard of procedure to protect online interaction. Finally, the questionnaire measures the online users' perceived complication level of regulations and procedures that intend to protect privacy and security in online environment, and measures the number of users' retreatments from completing online interactions due to mentioned complications by posing number of questions like "did you canceled an transaction or retreated to complete online interaction because of security or privacy protecting measures, choose: No at all, one time, two times, three times , more than three times..." to correlate directly the level of intention to continue using online services with the complicated protecting procedures. The questionnaire distributed in small cities in hungary, not in rural regions but not also in Budapest or large cities, to have responses from moderatedeveloped regions in regards of ICTs, it also directed to have more respondents who are over-40 years old.

The 135 questionnaire papers distributed in person and filled in the presence of interrogators to explain any ambiguous, taking in regard many of respondents are old, this field work took place between 15- 30 June, 2020, at the end the study has 127 valid responses.

\section{Sampling method}

The questionnaire distributed in small cities in hungary, not in rural regions but not also in Budapest or large cities, to have responses from moderate-developed regions in regards of ICTs, it also directed to have more respondent over 40 years old. The 135 questionnaire papers distributed in person and filled in the presence of interrogators to explain any ambiguous, taking in regard many of respondents are old, this field work took place between 15 - 30 June, 2020, at the end the study has 127 valid responses. 


\section{Result and discussion}

\section{Sample background analyzes:}

The $53 \%$ of respondents are females, and $43 \%$ males, $75 \%$ of respondents are over 40 years old, the age distribution illustrated in Figure 1.

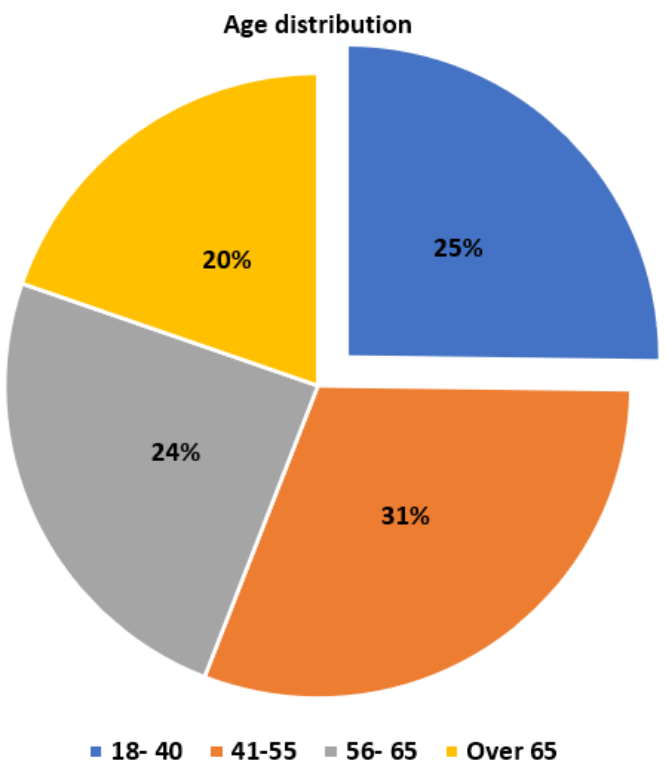

Figure 1. Age distribution of the sample.

Using SPSS program, this study has tested the correlation between people intention to use online services on one side and privacy and security regulations and procedures on the other side, there is a strong positive relation $(r=0.65, \mathrm{P}<0.001)$ between the people intentions to use online services on one side and privacy and security regulations and procedures on the other. In other words, increasing protecting procedures for online interactions is encouraging people to use e-government services, accomplishing their transactions online and interacting more freely on online space. But this result is not a surprising or new result, as many studies have reached the same result such as Schaupp and Belanger (2005) and Conklin and White (2006), so, this study considered this result just as a supportive outcome to be sure of the existence of mentioned relation in the study environment. A more focusing tests on the objective of this study have been done, a correlation test has been conducted between online users' age and users' retreating from accomplishing online interactions caused by perceived complications of applying protecting regulations and procedures on online interactions, the results are showed in table 1.

Table 1. Correlation test results between online user's age and his retreating from completing interactions caused by complications of protecting procedures

\begin{tabular}{|c|c|c|c|}
\hline \multicolumn{4}{|c|}{ Correlations } \\
\hline & & Real Age & Retreating Numbers \\
\hline \multirow{3}{*}{ Real Age } & Pearson Correlation & 1 & $0.730^{* *}$ \\
\hline & Sig. (2-tailed) & & .000 \\
\hline & $\mathrm{N}$ & 127 & 127 \\
\hline
\end{tabular}

From Table 1. there is a strong positive relation between users' retreating from accomplishing online interactions- caused by perceived complications of applying protecting privacy and security regulations and procedures- on one side and users' age on the other side $(\mathrm{r}=0.73, \mathrm{p}<0.01)$ which means as the online user is older as the perceived complications- that comes from online protecting procedures- increases the users' retreating from completing their transactions or any kind of interactions. 
For a deeper view, a regression analysis test has been conducted between the perceived complication of online protecting procedures and numbers of retreating from completing online interactions, the results are showed in the Table 2.

Table 2. Linear regression test results between perceived complication of online protecting procedures and users' retreating from completing av online interactions.

\begin{tabular}{|c|c|c|c|c|c|}
\hline \multicolumn{6}{|l|}{ Coefficients $^{\mathrm{a}}$} \\
\hline \multirow[b]{2}{*}{ Model } & Unstanc & ed Coefficie & $\begin{array}{l}\text { Standardized } \\
\text { Coefficients }\end{array}$ & \multirow[b]{2}{*}{$\mathrm{t}$} & \multirow[b]{2}{*}{ Sig. } \\
\hline & \multicolumn{3}{|c|}{\begin{tabular}{|l|l|l|} 
B & Std. Error & Beta
\end{tabular}} & & \\
\hline & -1.256 & .307 & & -4.088 & .000 \\
\hline $\begin{array}{l}\text { Perceived complication of online } \\
\text { protecting procedures }\end{array}$ & .070 & .006 & 730 & 11.929 & .000 \\
\hline \multicolumn{6}{|c|}{ a. Dependent Variable: Number of retreating from completing interaction } \\
\hline \multicolumn{6}{|l|}{ Model Summary } \\
\hline R Square & R Square & \multicolumn{2}{|c|}{ Adjusted R Square } & \multicolumn{2}{|c|}{ Std. Error of the Estimate } \\
\hline .730 & .532 & \multicolumn{2}{|l|}{.529} & \multicolumn{2}{|l|}{1.07411} \\
\hline
\end{tabular}

Table 2 shows that perceived complication of online protecting procedures has a significant impact on users' retreating from completing online interactions $(B=0.07, \mathrm{P}<0.001)$ and this perceived complication explains about $53 \%$ of the change in the users' retreating from completing online interactions (Adjusted R square $=0.529)$, which is a considerable percentage of explaining online users' retreating from completing online interactions.

As a result retreating from completing online interactions is highly impacted by the complications of online protecting procedures, this result is very important especially if we focused on financial transaction, so these procedures on one side encourage users to do their transaction online -as they feel safe to do it (as we see in first correlation test)- but on the other side when the users feels the complications of protecting procedures during accomplishing these transactions, the possibility to behave in a reversed way to their intentions and stop completing the transaction increase too, this drives to conclude that when protecting procedures of online interactions are designed the designers should take in consideration the difficulties and complications consequences that may impede users to complete the interactions online, and designers should find a design achieves the targeted protection level, and in the same time easy to be dealt by users.

To study the effect of perceived complications of online protecting procedures on older users, correlation and regression tests has been conducted, but this time only over 40 years old responses have been taken in consideration, the results are showed in table 3 and table 4 .

Table 3. Correlation analysis results between online over-40 years users' ages and their retreating from completing interaction caused by complications of protecting procedures

\begin{tabular}{|c|c|c|c|}
\hline \multicolumn{4}{|l|}{ Correlations } \\
\hline & & $\begin{array}{l}\text { Real Age (only } \\
\text { over } 40 \text { users) }\end{array}$ & Retreating Numbers \\
\hline \multirow[t]{3}{*}{ Real Age (only over 40 users) } & Pearson Correlation & 1 & $.792 * *$ \\
\hline & Sig. (2-tailed) & & .000 \\
\hline & $\mathrm{N}$ & 95 & 95 \\
\hline
\end{tabular}

Tables 3 shows a very positive strong relation $(r=0.79, \mathrm{P}<0.01)$ between over- 40 years online users' ages and retreating from completing online interactions caused by complications of online protecting procedures. From table 4 it can be noticed that perceived complication of online protecting procedures has a significant impact on over-40 years users retreating from completing online interactions $(B=097, \mathrm{P}<0.001)$ and this perceived complication explains about $62 \%$ of the change in the over-40 years users' retreating from completing online interactions (Adjusted $\mathrm{R}$ square $=0.623$ ), which is a considerable percentage of explaining online over-40 years users' retreating from completing online interactions. 
Comparing the results which concluded from tests illustrated in table 2 and table 4,shows that over-40 years online users' sensitivity to the increase of perceived complication caused by online protecting procedures is more by $9 \%$ compared to common online users (all ages), but this statistical comparison needs more supportive analysis to give a clearer understanding. To assess the over- 40 age online users' sensitivity to the perceived complication of online protecting procedures which hasn't a quite clear explanation by regression analysis alone, some additional descriptive analysis has been done

Table 4. Linear regression test results between perceived complication of online protecting procedures and over-40 years users' retreating from completing an online interaction.

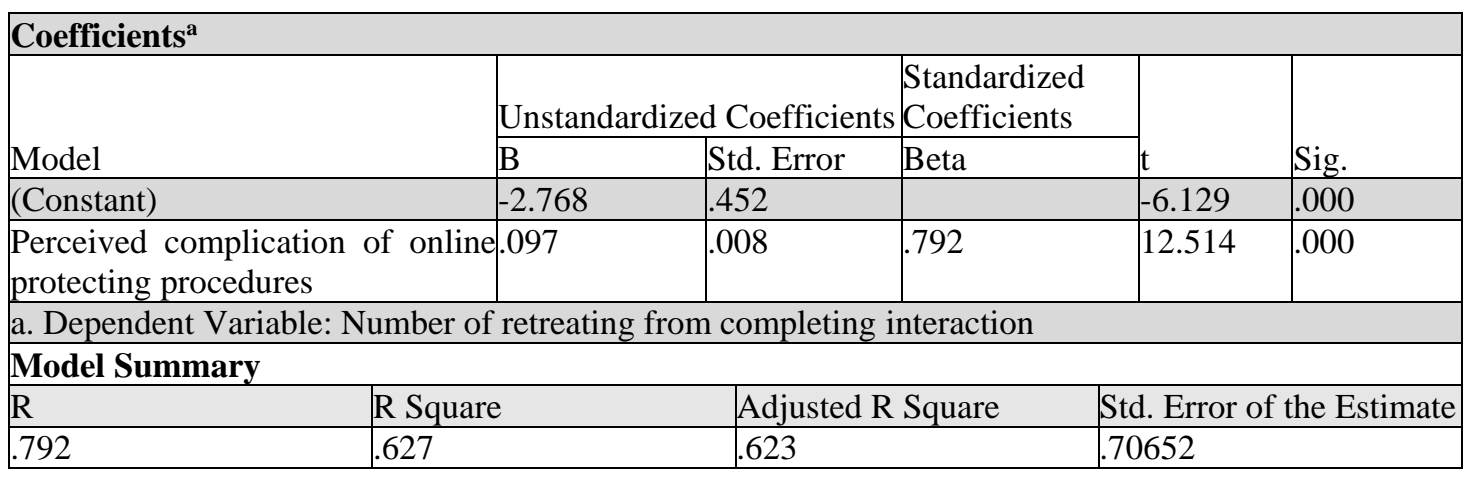

Only $21.8 \%$ of under-40 years users $(\mathrm{N}=32)$ have canceled at least one online interaction due to complications of protecting procedures whereas $95.7 \%$ of over- 40 years users $(\mathrm{N}=95)$ have did that, $89 \%$ of users between 41- 55 years old have canceled at least one online interaction due to complications of protecting procedures with cancelation average of 1.8 time in their lives, and all respondent over 55 years old have canceled at least one time with an average exceeds 3.5 times in their lives, but these averages of cancelation are not a precise indicator as some of users didn't perform any transaction if they didn't compelled to, and others just stop trying to perform online transaction after one or two retreating.

Moreover, $60 \%$ of persons between $40-55$ years old don't prefer doing their transactions online due to the complication of transaction security procedures and $51 \%$ of them asked for another person help, $72 \%$ of persons between 56- 65 tend not to use online services if they aren't compelled and 70\% of them asked for help from another person in accomplishing their transactions, where $92 \%$ of people over 65 are avoiding to do financial transaction online and they need another person help to perform it more than $82 \%$ of times. These results of high rates of asking other persons to help in accomplishing online transactions- which becomes higher with the increasing of users' age - expose online older users to the risk of deception from other persons.

Here, this study alludes that there is a responsibility of governments and financial institutions to develop special online protecting procedures concerning easy-dealing and flexibility with old users, and in the same time guarantee their privacy and data security, so, if e-services are served well to old people, it can be excellent served to all (Steele, 2016).

\section{Conclusion}

As e-governments are replacing conventional governments and spreading their services online, more and more people increase their interactions and accomplishing transactions online, which creates the necessity to exert regulations and procedures for protecting privacy and provide a secure medium, but these procedures have a lateral consequences such as complications and difficulties in accomplishing interactions online especially for old people, this research focused on this case and concluded that as the age of online user is increasing as his sensitivity toward complication of applying more online protecting procedures is increasing, also the probability of canceling an online transaction due to these complications increases too.

Besides to that the study concluded that as older as the online user- especially over 40 years old- as the more the user asking for other persons help to overcome the difficulties of online protecting procedures, which may expose those people to deception. This research suggests that governments- if they want to keep older aged people engaged- give a priority to enhance the flexibility and easiness of online protecting 
measures for all user ages, and in the same time serves the targeted protection level. Also, this study suggests extending this research, or conducting a new research to observe the impacts of complications and difficulties that consequence from online privacy and security protecting procedures in lower and higher developed ICTs areas, by covering both rural areas and large cities in Hungary as an example of eastern European countries.

\section{Limitation of the study}

The questionnaire was not distributed randomly, but it was distributed to have more over-40 years old respondents. Also, due to cost and time limitation, this study accepted to distribute the questionnaire in small cities in Hungary, not in rural areas but not also in the large cities, as moderate-developed regions in regards of ICTs development, leaving an extended survey that covers all Hungarian territory to a further future research.

\section{References}

[1] Age UK: 2015. Only the tip of the iceberg: Fraud against older people. Age UK. London.

[2] Ahmad, M., Markkula, J. and Oivo, M: 2013. Factors Affecting E-Government Adoption in Pakistan: A Citizen's Perspective. Transforming Government: People, Process and Policy. Vol. 7 No. 2. pp. 225239. http://dx.doi.org/10.1108/17506161311325378.

[3] Alomari, M., Sandhu, K. and Woods, P: 2009. E-Government Adoption in the Hashemite Kingdom of Jordan: Factors from Social Perspectives. Proceedings of the International Conference for Internet Technology and Secured Transactions, London. 9-12 November 2009, pp. 1- 7.

[4] 6. Al-Shboul, M., Rababah, O., Ghnemat, R. and Al-Saqqa, S: 2014. Challenges and Factors Affecting the Implementation of E-Government in Jordan. Journal of Software Engineering and Applications, Vol. 7. pp. 1111- 1127.

[5] Angst, C. M., and Agarwal, R: 2009. adoption of electronic health records in the presence of privacy concerns: The elaboration likelihood model and individual persuasion. MIS Quarterly. Vol. 33 No 2. pp. 339- 370.

[6] Belanger, F., and Carter, L: 2008. Trust and risk in e-government adoption. Journal of Strategic Information Systems. Vol. 17. pp. 165- 176.

[7] Bercovitz, K., Pagnini, F:2016. Mindfulness as an opportunity to narrow the grey digital divide. In: Villani, D. (ed.) Integrating Technology in Positive Psychology Practice, pp. 214- 228. IGI Global. http://doi.org/10.4018/978-1-4666-9986-1.ch009.

[8] Bergstrom, A: Online privacy concerns: a broad approach to understanding the concerns of different groups for different uses. Computers in Human. Behavior. Vol. 53. pp. 419- 426. DOI: 10.1016/j.chb.2015.07.025.

[9] Blank, G., Bolsover, G., Dubois, E: 2014. A new privacy paradox: young people and privacy on social network sites. SSRN Electronic Journal. Article (PDF Available) in SSRN Electronic Journal. DOI: 10.2139/ssrn.2479938.

[10] Conklin, A. and White, G. B.: 2006. E-government and cyber security: the role of cyber security exercises. Proceedings of the 39th annual hicss. Ieee computer society.

[11] Coventry. L. and Briggs. P: 2016. Mobile technology for older adults: Protector, motivator or threat?. In: Zhou J., Salvendy G. (eds) Human Aspects of IT for the Aged Population. Design for Aging. ITAP 2016. Lecture Notes in Computer Science. Springer, Cham. Vol 9754. pp. 424- 434. https://doi.org/10.1007/978-3-319-39943-0_41.

[12] Davidson, S: 2018. Digital Inclusion Evidence Review 2018. Report. UK Age. London. [Retrieved]: https://www.ageuk.org.uk/globalassets/age-uk/documents/reports-andpublications/age_uk_digital_inclusion_evidence_review_2018.pdf

[13] European Commission: 2020. The Digital Economy \& Society Index (DESI). [Available online]: https://ec.europa.eu/digital-single-market/en/desi\#the-digital-economy-and-society-index-desi. [Accessed on July $\left.4^{\text {th }}, 2020\right]$.

[14] Garg, V., Lorenzen-Huber, L., Camp, L. J., and Connelly, K: 2012. Risk communication design for older adults. Gerontechnology. Vol. 11 No. 2. pp. 166- 173.

[15] Hoofnagle, C., King, J., Li, S., Turow, J: 2010. How different are young adults from older adults when it comes to information privacy attitudes and policies. Scholarly Commons, Annenberg School 
for Communication, University of Pennsylvania. retrieved from http://repository.upenn.edu/asc_papers/399. DOI:10.2139/ssrn.1589864.

[16] Hornung, D., Müller, C., Shklovski, I., Jakobi, T and Wulf, V: 2017Navigating relationships and boundaries: Concerns around ICT-uptake for elderly people. In Proceedings of the $2017 \mathrm{CHI}$ Conference on Human Factors in Computing Systems. CHI '17. pp. 7057- 7069.

[17] Karp, N., and Wilson, R: 2011. Protecting Older Investors: The Challenge of Diminished Capacity. AARP Public Policy Institute Research Report No. 2011-04. New York, NY: AARP Public Policy Institute.

[18] Kowalewski, S., Ziefle, M., Ziegeldorf, H., Wehrle, K: 2015. Like us on Facebook! - analyzing user preferences regarding privacy settings in Germany. Procedia Manufacturing. Vol. 3 No. pp. 815-822. DOI: 10.1016/j.promfg.2015.07.336.

[19] Millward, P.: 2003. The 'grey digital divide': perception, exclusion and barriers of access to the internet for older people. First Monday. Vol. 8 No. 8.

[20] Miltgen, C.L., Peyrat-Guillard, D: 2014. Cultural and generational influences on privacy concerns: a qualitative study in seven European countries. European Journal of Information Systems, Palgrave Macmillan. Vol. 23 No. 2. pp. 103-125.

[21] OECD: 2012. Report on Consumer Protection in Online and Mobile Payments. OECD Digital Economy Papers, No. 204, OECD Publishing, Paris. http://dx.doi.org/10.1787/5k9490gwp7f3-en

[22] Osborne, S. and Brown, L: 2011. Innovation, public policy and public services delivery in the UK. The word that would be king?. Public Administration. Vol. 89 No. 4. pp. 1335- 1350.

[23] Parasuraman, A., Zeithaml, V. A., and Malhotra, A: 2005. E-S-QUAL a multiple-item scale for assessing electronic service quality. Journal of Service Research. Vol. 7 No. 3. pp. 213- 233.

[24] Parent, M., Vandebeek, C. A. and Gemino, A. C: 2005. Building citizen trust through e-government. Government Information Quarterly. Vol. 22 No. 4. pp. 720- 736.

[25] Sarah, L., Lock, JD: 2016. Age-friendly Banking: How we can help get it right before things go wrong. Public Policy and Ageing Report 2016. The Gerontological Society of America, Oxford University Press. Vol. 26 No. 1. pp. 18- 22.

[26] Schaupp, L. C. and Belanger, F.: 2005. A conjoint analysis of online consumer satisfaction. Journal of Electronic Commerce Research. 6(2), 95-111.

[27] Schreurs, K., Quan-Haase, A., Martin, K: 2017. The older adult's digital literacy paradox: aging, media discourse, and self-determination. Canadian J. Commun. Vol. 42. pp. 1- 35.

[28] Steele, D.: 2016. Age-friendly Banking: What it is and how you do it. Report. Age UK. Tavis House. London. [Available online]: https://www.age-platform.eu/publications/age-friendly-banking-what-itand-how-you-do-it. [Retrieved July, $6^{\text {th }}, 2020$ ].

[29] Taddicken, M: 2014. The 'Privacy Paradox' in the social web: the impact of privacy concerns, individual characteristics, and the perceived social relevance on different forms of self- disclosure. Journal of Computer-Mediated Communication. Vol. 19 No. 2. pp. 248- 273. DOI: https://doi.org/10.1111/jcc4.12052.

[30] Toots, M: 2019. Why E-participation systems fail: The case of Estonia's Osale.ee. Government Information Quarterly. Vol. 36 No. 3. pp. 546- 559. https://doi.org/10.1016/j.giq.2019.02.002. Elsevier Inc.

[31] Van den Broeck, E., Poels, K., Walrave, M: 2015. Older and wiser? Facebook use, privacy concern, and privacy protection in the life stages of emerging, young, and middle adulthood. Soc. Media + Soc. Vol. 1 No. 2. pp. 1- 11.

[32] Van Dijk, J: 1999. The one-dimensional network society of Manuel Castells. New Media Soc. Vol. 1 No. 1.pp. 127- 138.

[33] Waidner, M. and Kasper, M: 2016. Security in industrie 4.0: challenges and solutions for the fourth industrial revolution. Conference Paper. Proceedings of the 2016 Conference on Design, Automation and Test in Europe. pp. 1303-1308. DOI: 10.3850/9783981537079_1005.

[34] West, S: 2015. Later life in a digital world. Age UK report. Age UK, 2015. [Available online]: https://www.ageuk.org.uk/globalassets/age-uk/documents/reports-and-publications/reports-andbriefings/active-communities/later_life_in_a_digital_world.pdf. [Downloaded, July $\left.7^{\text {th }}, 2020\right]$. 